\title{
Transition from Kindergarten to Elementary School: Shanghai's Experience and Inspiration
}

\author{
Xuan Zhao \\ School of Social Development and Public Policy, Fudan University, Shanghai, China \\ Email: 13482640049@sina.cn
}

How to cite this paper: Zhao, X. (2017). Transition from Kindergarten to Elementary School: Shanghai's Experience and Inspiration. Creative Education, 8, 431-446. https://doi.org/10.4236/ce.2017.83033

Received: February 16, 2017

Accepted: March 28, 2017

Published: March 31, 2017

Copyright (C) 2017 by author and Scientific Research Publishing Inc. This work is licensed under the Creative Commons Attribution International License (CC BY 4.0).

http://creativecommons.org/licenses/by/4.0/

\begin{abstract}
Since early 1980s, research of transition from kindergarten to primary school was conducted in kindergartens at Shanghai, which mainly focused on how kindergarten children prepared for early primary school. The research group of Teachers Training College of Yangpu District in Shanghai (TTCYD) carried on research on transition education from kindergarten to primary school (K-P transition education) since 2008. This study points out that transition education from kindergarten to primary school (K-P transition education) usually covers from senior class in kindergarten to pre-primary school. Transition education from kindergarten to primary school in this paper mainly focuses on the period from last year of kindergarten to the first year of primary school as community, schools and families try to adapt to the development of every student, and help young children to achieve a smooth transition from kindergarten to primary school. The core of the project is to explore the curriculum elements of K-P transition education through theoretical analysis and practice, cultivate high-quality intercommunication teachers, establish the evaluation content of K-P transition education, as well as construct cooperative mechanism between family and school, to improve children's adaptation between transfer from kindergarten to primary education, and realize smooth, healthy and happy transition from kindergarten to primary school. Finally, this paper depicts K-P transition ecological system of Yangpu District, which has significance in K-P transition education practice and theory.
\end{abstract}

\section{Keywords}

Transition from Kindergarten to Elementary School,

Kindergarten Education, Elementary School Education,

Teachers Training College of Yangpu District, Shanghai, China

\section{Introduction}

As early as the 1980s, research of transition from kindergarten to primary school 
was once conducted in kindergartens at Shanghai. This research mainly focused on how kindergarten children prepared for early primary school in terms of behavior, psychology and knowledge. This research usually paid more attention on actions and changes in kindergarten, such as to let kindergarten children join pre-primary school seminars, teach kindergarten children how to behave in primary school, and learn to spell and calculate earlier. Although the results of those transition activities from kindergarten to primary school were adequate, it turned out that those transition activities not only imposed heavy study load on children but also introduced the problems such as study adaptability and social adaptability because of the curriculum difference between kindergartens and primary schools. Differences do exist in education concepts, curriculum architecture, teaching models and evaluation methodology between kindergartens and primary schools. In the context of curriculum innovation, it is obvious that pre-primary school seminars don't fit for the highly development trend of general education. The general principles of "Kindergarten Education Guidelines (Trial)", issued by Chinese Ministry of Education in July 2001, emphasize that the content of Kindergarten educations should be comprehensive, enlightening, pay close attention to the personal sound development of children (Ministry of Education of the People's Republic of China, 2001). Kindergarten should cooperate with families and communities to interact with primary schools. It also pointed out that kindergarten education is an important part of basic education, as well as fundamental phase in local school education and lifelong education. It was proposed that early childhood education must serve for the entire life development for the first time.

However, the reality is that prevalence of disjointed phenomenon is common during transition from kindergarten to primary school, so most young children cannot quickly adapt to primary education. Teachers' teaching methods and evaluation concepts, as well as parents' parental concepts, pay more attention on imparting knowledge. Cultivation of young children's attitudes, habits, and abilities has been neglected during transition education so that the development of children's personality is less. The first grade freshmen, parents and teachers suffer general anxiety (Cui, Liu, \& Li, 2011).

In response to this situation, in 2007, Shanghai Municipal Education Commission issued "Shanghai primary and secondary school curriculum adjustment program". And in 2008 and 2009 Shanghai Municipal Education Commission introduced transition curriculum implementation requirements from kindergarten to primary school (K-P).

The first month after primary school enrollment should be set as study preparation period. Meanwhile the last two months of kindergarten classes should also be set as preparatory period. Kindergartens and primary schools should pay more attention on the children's development stage and continuity of education, follow the rule of physical and mental development of young children, set the appropriate growth slope for children, and alleviate primary school enrollment pressure. The implementation of this requirement requires the active participa- 
tion of school teachers, as well as a good internal environment and external environment of social support.

In September 2013, Shanghai Municipal Education Commission issued document on the implementation of the "Curriculum Standards-based Teaching and Evaluation in Primary School of Shanghai". Education policies were stipulated on the basis of the current part that young children learned a lot of knowledge earlier. To a certain extent, this guide lines called on teachers and parents to update the concept of transition education from kindergarten to primary school, ease their tension. And the most important thing is to reduce the burden on young children's learning and promote their development of physical and mental health. At this point, transition education from kindergarten to primary school, once again become urgent and need more attention in basic education (Shanghai Municipal Education Commission, 2013).

Teachers Training College of Yangpu District in Shanghai (TTCYD) was established in 1958. It is led by Yangpu District Education Bureau, and is responsible for regional teacher training. The research group of Teachers Training College of Yangpu District in Shanghai (TTCYD) carried on random sampling survey on thousands of pre-primary school students' parents since 2008. The survey found out that about $64 \%$ pre-primary school students had participated in extracurricular remedial classes for phonics, literacy, maths or English; $43 \%$ of them started extra-curricular classes outside of senior class of kindergarten; $54 \%$ of them learn of reading phonetics; $86 \%$ of them learned addition and subtraction within the number of 100; 66\% of them have learned English (Lin, 2011). Besides, only $21 \%$ of pre-primary school students often took part in games, small experiments, and handcraft, and $36 \%$ of tested parent worried about their children's literacy and numerate.

Thus, the actual learning of young children has gone beyond the curricular standards of early childhood education, but a considerable number of parents, kindergarten and primary school teachers still think that this phenomenon is normal. Even some parents feel anxious of their children learn less than others, in order not to let their children lose at the starting line, they send pre-school children to attend afterschool classes like phonics, literacy, math and English (Wu \& Zhu, 2014).

More and more scholars discuss from the perspective of education, psychology, sociology and ecology theory, finally find that non-intellectual factors play a key role in process of children's growth. Pre-primary education too early, especially teaching phonetic, literacy, mathematics and other aspects of knowledge, is not the most important ability in K-P transition education. While children's emotional attitude, social ability, problem solving ability, socialization, and physical fitness are key factors for the healthy growth of children's life. This research focus on domestic practice in Shanghai, from regional perspective, promotes overall design to relieve the current problems during K-P transition education. Research based on kindergarten teaching activities and primary school learning activities, try to carry out convergence studies (Cui, Liu, \& Li, 2011; Shao, 2013).

Through field work and regional practice of K-P transition education, educa- 
tors and researcher suggest that: what should pre-primary children learn and how can they learn after school? What should teachers teach and how can they teach in senior kindergarten as well as first grade in primary school? What kind of evaluation methods can promote the young Children's learning and self-development? How to combine the strength of parents to do a good job of K-P transition education? What should the region education authorities and Teachers Training College of Yangpu District in Shanghai (TTCYD) do? These problems are Yangpu District currently faced, which will inevitably have a significant impact on the development of young children (Zhu, 2013).

\section{Theoretical Background}

From the perspective of Educational Psychology, Benjamin Bloom carried out continued research on the critical period of children's intellectual development, nearly 1,000 people involved. This study found out that $80 \%$ of the human intelligence formed before the age of 8 children, and grew fast from 4 to 7 -year-old. Stage from 4 to 7 year old is the best period for the development of children's imagination, as well as cultivating the critical period of social emotions and behavior.

Effective attention time for young children is 10-15 minutes. Therefore, the curriculum designed for transition from kindergarten to elementary school should meet this rule, in order to gain children's attention. In addition, during transition from kindergarten to primary school children will experience excitement, boredom and adaptation period of three stages.

Most young children suffer a fluctuating period before enrollment, mainly because of the lack of psychological preparation, cooperation consciousness, and misunderstanding of the primary school (Wang \& Yang, 2011).

Brofen Brenner put forward the view of "ecological convergence" while talking about the transition from kindergarten to elementary school in 1979, which he called "ecological transition". And he pointed out that transition mainly includes two aspects: setting change and role change (Brofen Brenner, 1979).

Kagan Sharon Lynn considered that transitions were a strategy to overcome the problem of overexploitation due to discontinuity, when discussing the continuity of experience (Kagan, 1991).

Neuman further pointed out that children would experience many "vertical transitions" and "horizontal transitions", according to Kagan's concept of continuity. "Vertical transitions" concluded such as entering the kindergarten from the family or entering primary school from the kindergarten. "Horizontal transitions" usually mean "level of convergence", such as a person transferred from the place of home from to the playground in daily life (Neuman, 2002).

From the perspective of ecology, studies have found out that during the transition period, the relationship between children, family, peer and community made direct or indirect effects on the dynamic relationship network, so the construction or improvement of this network can play a positive and supportive role on the transition period (Cui, Liu, \& Li, 2011).

On the basis of this, Donlup thinks that ecological environment for development of children is composed of four nested systems: the first layer is a micro 
system, including kindergartens, schools and families. The second layer is the view of the system, individuals through interaction and influence connect with micro system and finally become part of it (Fabian \& Dunlop, 2002). For example interpersonal relationship in the classroom, the school curriculum and teaching activities are influenced by the environment, as well as affect the environment. The third layer is the appearance of the system, including reforming the local education policy, social services, medical insurance, housing conditions, parents' occupation, intervention projects, local communities and other aspects of the children, although not directly experienced, but indirectly through a profound impact on children. The fourth layer is the macro system, refers to a more general effect, including policy, the government's social and political system, culture, ideology and social value, as well as the rights and obligations, these aspects will also have an indirect effect on children. Above all the intersection of four systems constitutes a complex map of the ecosystem (Li, 2011).

In addition, from a management system perspective, school is an open system composed of students, teachers, school administrators, as a sub-system of society. Barnard proposed that the organization is part of the social system in his social systems theory, as long as in a system organization cannot be separated from the other subsystems and the whole system. Therefore, as a subsystem of the social system, school should connect with social system and other subsystems, such as family, community and so on (Zhang \& Fu, 2012).

From the above theoretical analysis, it can be seen K-P transition education is a complex problem involved two sections from kindergarten to primary school, the characteristics of students' physical development ,mental development and cognitive, and the interaction and influence of teachers, parents and society. The main body of the starting is to explore the connotation of the understanding of young convergence from a broader level to understand and grasp in order to find a suitable solution to the problem of young bridging the path of education.

\section{Research Problem}

The development of education reform, and teacher professional development need research carried on K-P transition education. K-P transition education also is the demand of the lifelong development of young children. This study is based on the "linkage between kindergarten and primary school" strategy, rooted in action and practice, and finally aims at solving key problems in K-P transition education. This paper depicts K-P transition ecological system of Yangpu District, constructs, explore the curriculum elements of K-P transition education through theoretical analysis and practice, cultivate high-quality intercommunication teachers, establish the evaluation content of K-P transition education, as well as construct cooperative mechanism between family and school, which has significance in K-P transition education practice and theory.

\section{Objective of the Study}

The core of the project is to explore the curriculum elements of K-P transition 
education through theoretical analysis and practice, cultivate high-quality intercommunication teachers, establish the evaluation content of K-P transition education, as well as construct cooperative mechanism between family and school, to improve children's adaptation between transfer from kindergarten to primary education, and realize smooth, healthy and happy transition from kindergarten to primary school (Cui, Liu, \& Li, 2011).

\section{Significance of the Study}

The core of the project aims to solve the problem of disjointedness between kindergarten and primary education, focus on the cultivation of interest, habits and emotions of young children in the early stage of convergence, which alleviates the burden of the first grade students. It fully embodies the concept of "humanistic education", try to adapt to the development of every student, help young children to achieve a smooth transition from kindergarten to primary school. The research aims to adjust the curriculums and activities during transition period from kindergarten to primary school, help teachers to find key point of convergence, share the limited resources of the complementary educational resources in region of Yangpu District in Shanghai, lay theoretical and practical foundation for regional K-P transition education of young children.

\section{Definition of Terms}

Transition education from kindergarten to primary school (K-P transition education) usually covers from senior class in kindergarten to pre-primary school. Transition education from kindergarten to primary school in this paper mainly focus on the period from last year of kindergarten to the first year of primary school, as community, schools, and families, try to adapt to the development of every student, help young children to achieve a smooth transition from kindergarten to primary school.

\section{Research Questions}

This paper focuses on four research questions as follows:

First of all, schools explore the curriculum elements of K-P transition education through theoretical analysis and practice, develop more suitable transition course for young children's learning and daily life.

Secondly, educational administration department, universities and teacher colleges cultivate interoperability teachers who can integrate different teaching methods in two school section.

Thirdly, educational administration department and educational researchers design the developmental evaluation index system suitable for young children in $\mathrm{K}-\mathrm{P}$ transition period.

Last but not least, educational administration department, educational researchers and schools construct home-school cooperation mechanism, encourage parents and schools play a role in K-P transition education. 


\section{Methodology}

Action Research. Action research emphasizes that researchers take part in depth practice, carry out field research, and establish equal and collaborative relations with research objects, finally achieve contextualization and contextualization of this study. 26 experimental schools take part in the research, with 13 kindergartens and 13 primary schools set equality and interaction relationship. As kindergarten teachers and primary school teachers join together seek improvement, and ultimately promote the overall development of K-P transition education.

Literature Research. Many researches carried on transition education from kindergarten to primary school, which can be reference.

Investigation and Interview. This study carry out investigation focused on common problems in teaching activities, teaching methods, convergence curriculum and family education during transition from kindergarten to elementary school. At the same time this study interview students, parents, teachers, comprehend their needs and confuse during transition education, track the effectiveness of research to make the subject more in line with the actual needs of education and teaching. So as to form a circular research method of "theoretical study-problem exploration-empirical summary-practice-transfer and refinetheoretical guidance", which makes the project prove and circulate in theory and practice, finally improve the research targeted and practical.

\section{Results of the Study}

\subsection{Construct Regional Educational Ecology Circle of K-P Transition Education}

From the perspective of ecology, children, families, schools and community environment form a dynamic network, which have direct or indirect effects on transition education. Improving this network can make children in a positive and supportive role in the dynamic environment for the successful completion of transition from kindergarten to elementary school (Fabian \& Dunlop, 2002). This study refers to Dunlop constructed complex ecological education system map, and proposes ecological education system of transition education from kindergarten to elementary school in Yangpu district of Shanghai (Figure 1).

The inner circle refers to the microscopic system of the transition education, which consists of four sub-topics. The core is the growth of young children. Teachers and parents play an interactive and main role on influencing young children, and school curricula and evaluation mechanisms also influence young children. At the same time, children, as the audience of educational objects, respond to the voice from all sides. The whole system presents interactive effects and common growth ecology (Zhu, 2013).

The middle circle represents the mesoscopic system of the transition education in this area, which is directly related to the education policy and community environment. As a key research item at the regional level, this project will have a certain influence on the educational policy and teaching concept of the district, 


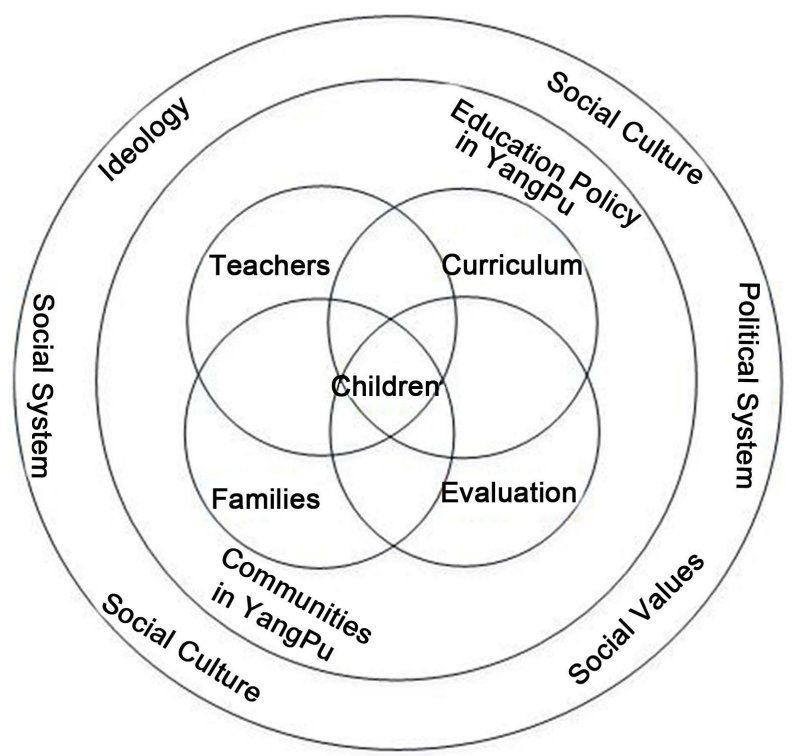

Figure 1. Ecological education system of transition education from kindergarten to elementary school in Yangpu district of Shanghai.

and promote the development of the transition education in the meso level (Zhu, 2013).

The outer circle covers the macroscopic system of the transition education in this area, i.e., the ideology, social system, political system, economic environment, social and cultural background, and corresponding social values in Shanghai, the most prosperous metropolis in China.

Our research can be generalized although it was based on the level of regional research. The four sub-topics are aimed at the micro, meso and macroscopic three-dimensional system. Based on teaching practice, action research and experimental research, we establish the transition education theory in our district (Wu \& Zhu, 2014).

However, the research team also found that in the condition that the macrosystem of the outer circle has not changed, the education system, teacher resources and family education in this district can only be exerted from the microcosmic system and the mesoscopic system to influence children's transition education, to enable young children to have the right to give opinion in interaction, to jointly promote the formation of regional transition educational ecology (Wu \& Zhu, 2014).

\subsection{Develop Curriculum Resources for K-P Transition Education}

For the target of convergence, the longitudinal design of the transition curriculum reflects progressive of two school sections. The horizontal design of the transition curriculum from the perspective of "content synthesis" has overcome the "knowledge centered" teaching mode. Comprehensive practical activities of the first year in primary school have similar curriculum objectives with life adaptability course in kindergarten classes. Curriculum objectives of two school sections show consistency and continuation. The paper calls that transition cur- 
riculum in the first year of primary school should adjust the content and objectives of subject, reduce knowledge learning, develop activity course, and expand game-based teaching methods.

In this paper, the construction of transition curriculum aims to focus on the following three dimensions:

Adapt to school campus and study environment: as young children like their new school, teachers and classmates, willing and active, participate in school and class activities.

Habit training: the basic understanding of the school life related to manners, learning habits, hygienic habits, physical exercise, etc., can actively put into action and gradually into a good habit.

Emotional Cultivation: interested in learning, activities, curiosity and thirst for knowledge.

\subsubsection{Emphasize Kindergarten Children's Adaptation to Primary School Environment}

Constructivism holds that society is formed by process of mutual construction between man and man, man and environment. Education, as an important part of society, is not only a process of interaction between teachers and students, students and students, teachers and teachers, but also product of the interaction between students and society, students and communities, students and schools, students and classrooms. Based on the system theory of ecology and management, this paper takes the students as the center, respects the characteristics of students' physical growth, mental growth, as well as cognitive development. In addition, after Dewey proposed his point of view "school is society", Chinese scholar Yan Yangchu proposed his point of view "society is school", and both connect school with society. There is a close relationship between growth of students with environment. Therefore, research group adjust curriculum content in the kindergarten, pay attention to creation of environment for the growth of children, especially classroom environment (Wang \& Yang, 2011).

In the preparation of "Teachers' Handbook for transition education from kindergarten to elementary school", researchers guide teachers to redesign common wall, blackboard, book corner, natural angle and living cabinet. Use environmental arrangements to help students do a good job when they are on duty, set the problem wall, provide life tips and so on. Through creation and reset of classroom environment, promote students' physical and mental development in two school sections, finally achieve transition education.

\subsubsection{Cultivation of Children's Social Behavior and Rule Consciousness}

Both kindergarten and primary schools emphasize children's development of good social behavior habits. Help children adapt to primary school life as soon as possible in order to successfully achieve transition from kindergarten to preprimary school, such as help children develop good habit of listening (Wang \& Yang, 2011).

Emphasize children's rule consciousness. The consciousness of rules and ability to carry out rules has great effect on personal life. When children enter kin- 
dergarten they must comply with the rules of kindergartens. As children enter primary school, they must comply with the rules of primary schools. Growth of children from kindergarten to primary school is the first turning point in their life. So researchers try to link two school sections, cultivate young children's awareness and ability to consciously abide by the rules (Zhang \& Fu, 2012).

The task of improving children awareness and ability. Young children's awareness and ability training is central task in primary school and kindergarten. Study is carried out from three aspects of children, teachers and parents. From children's perspective, children's physical and mental development has continuous stage. Cultivate children's consciousness is the task for perceiving and understanding of themselves. Complete this task includes cultivating individual's sense of responsibility, self-consciousness, ability to finish basic task in the process. Starting from the perspective of teachers, researches focus on guiding teachers to pay attention to children' interests, habits and emotions, help teachers to set up correct view of K-P transition education, and provide teaching strategies for training children to gain task consciousness. From parents' perspective, the study helps them correct their misunderstanding over K-P transition education, and provide guidance for parents to carry out effective task awareness training for their children (Wang \& Yang, 2011).

\subsubsection{Emphasizes Emotion Cultivation of Children during K-P Transition Education}

From the perspective of students' learning motivation, eager of knowledge and pursuit of truth are lasting driving force to promote children's learning. Therefore, recent K-P transition education emphasis on knowledge transfer, at the same time, it needs to pay more attention to children's understanding of knowledge, not only just remember knowledge. In addition, from the point of view of human social development, education is the process of learning to be a social person. Therefore, the cultivation of emotion is an important basis for formation of communication ability with others, personal attitudes and values. K-P transition education is a critical period of personal social development, while personal emotional cultivation should be emphasized on. Along with the advancement of kindergarten, researchers pay more attention to children's adaption to the environment and rules of curriculum, while more and more children will foster personal emotion into the curriculum design. For example, "game of science" subject focus on cultivating emotional attitudes and values, children are required to carry out various scientific game to achieve subjects target, maintain and develop the scientific phenomena of curiosity and thirst for knowledge, respect observed scientific fact. Cooperate with others to carry out a variety of Scientific Games in classroom, children can take the initiative to ask questions, participate in the exchange, fully express their views, and listen carefully to others (Li, 2011).

\subsubsection{Explore "Game Teaching Methods" during K-P Transition Education}

Childhood is precious period when children have the most pure sense, they get 
happiness in the game. Chinese Ministry of Education issued " 3 to 6 year old children's learning and development guidelines" which clearly pointed out that children's learning is based on direct experience from game and daily life. Jean Piaget, a famous child psychologist, also said: "wisdom originated in daily activity, which is also the bridge between the subject and object" (Zhang \& Fu, 2012). Therefore, we should pay special attention to the unique value of playing game, the creation of a wealth of educational environment, to maximize support and meet the needs of young children through direct perception, practical operation and experience to obtain experience. Our group explored the "game teaching methods" of the kindergarten, which has positive response to this file requirements and growth of children (Cai, 2011).

Emphasize Penetration of Cooperative Games and Learning in Cohesion. Cooperation game of infant stage is an important channel for children's learning experience, but once into the primary school stage, cooperative game mode will be replaced by thirty-five minutes of classroom teaching and learning mode has changed. These changes not only make the children have a great deal of adaptation and anxiety, but to a certain extent, hinder the further improvement of the children's ability to cooperate. Based on such problems, pre-primary school and senior kindergarten both at breakthrough point, try to find a way to connect the infant stage, as carry out cooperative game and cooperative learning in primary school. Encourage teachers to find problems, reflect problems, improve the problems in the operation, so as to improve the effectiveness of K-P transition education (Li, 2011).

\subsection{Foster Teachers' Interoperability for K-P Transition Education}

The training of teachers can be divided into two parts: exploration of theory and promotion of practice. Through theoretical analysis, teachers learn about $6-8$ years old children's physical and mental development characteristics of cognitive thinking; through mutual visits and joint research, explore "game teaching mode" suitable for kindergarten education. On basis of this, interoperable teachers should improve educational concept, adjust teaching behaviors, and establish harmonious relationship between kindergarten and primary school (Zhang \& Fu, 2012).

\subsubsection{Think about the Understanding and Expectation of Teachers}

Set Training Objectives of Regional Teachers. Considering training objectives of interoperable teachers from regional view, teachers should be familiar with the features of senior kindergarten section and pre-primary school section, master main teaching methods, so that young children can experience a smooth transition and continued development. First of all, teachers need to take cognizance of changes in the K-P transition education. Secondly, interoperable teachers should understand mental characteristics of 6 to 8 years old children, know kindergarten children's learning needs and interests, understand of children's habits and emotions development in kindergarten, grasp problem solving methods. Third- 
ly, interoperable teachers understand teaching environment, practical understanding of children's cognitive ability, behavior, etc., design activity curriculum and game, find suitable teaching methods. Finally, interoperable teachers should also be able to work collaboratively with parents.

Obtain Cross School Section Internship Experience and Perception. Only the theoretical study is far from enough, interoperable teachers should also obtain personally experience and perceptions. Researchers ask interoperable teachers to enter kindergarten classroom and primary school classroom. Teachers from kindergarten spend one day a week staying in primary school for six weeks, while teachers from primary school spend one day a week staying in kindergarten classroom. Interoperable teachers spend one day a week to enter each other's school to prepare lessons, create classroom environment, and participate in teaching and research activities, finally evaluate children's development. Through exchange program, many teachers get personal experience and perception of K-P transition education (Zhang \& Fu, 2012; Gu, 2014).

\subsubsection{Understand Characteristics and Requirements of Two Educational Sections}

Understand physical and mental development of young children during K-P transition education, comply with cognitive rules (Wu \& Zhu, 2014). First of all, the stage of K-P transition is important stage of children's imagination and intelligence development, as well as key period of social emotion and behavior establishment, including gender identity, self-esteem and self-regulation. During K-P transition young children experience social interaction, cooperate with new classmates, and learn to obey social rules and moral principles. Secondly, during $\mathrm{K}-\mathrm{P}$ transition young children are in the cognitive transition period from "pre-computing stage" to "concrete computing stage". They used to concrete thinking not abstract thinking. Although the image thinking still occupies the dominant position, children's thinking has begun to develop.

\subsubsection{Explore "Game Teaching Methods" Suitable for K-P Transition Education}

In regional teachers' exchange program, pre-primary teachers try to transfer "game teaching method" of kindergarten to first grade of primary school. Through the materialization of activities, the process of game, the activities of a wide range of evaluation for teaching methods, children experience the process of operating plays, protect children's desire of knowledge and learning interests, stimulate children initiative to master skills (Fan, Fan, \& Chen, 2010; Wu \& Zhu, 2014).

Therefore, interoperable teachers believe that the important learning method of K-P transition education is "game teaching method". Kindergarten teachers generally master game teaching methods relatively mature. As kindergarten teachers and primary school teachers practice of game-based teaching method in $\mathrm{K}-\mathrm{P}$ transition course during regional teachers' exchange program, which can help pre-primary school teachers to learn faster and use "game teaching me- 
thods" in classroom, help young children to get more perceptual knowledge and rational learning for the future.

\subsubsection{Improve Educational Philosophy and Behavior of Teachers}

Through the practice of "regional teachers' exchange program", pre-primary school teachers who have ever participated in this program have greatly changed educational concept and personal views of educational philosophy, bring interoperability changes in teacher behavior and improvement (Wu \& Zhu, 2014).

In the past, some pre-primary school teachers consider that some young children who have just entered primary school are very "unintelligible" and difficult to teach. But they do not pay much attention to children's ideas and opinions, and often manage their students with their own authority. Since preprimary school teachers take part in kindergarten's lectures, classes, assessment and a series of activities. Pre-primary school teachers have gradually found out that children's ideas need more attention and protection. Pre-primary school teachers need to respect the right of children to speak. Teacher-student relationship is more equal and cordial than before. At the same time, through regional teachers' exchange program, pre-primary school teachers learn more about kindergarten's teaching methods. The behavior of young children do not immediately reach the requirements of primary education, teachers should give more tolerance, appropriate criticism, and guidance (Li, 2011).

At the same time, through regional teachers' exchange program, kindergarten teachers acquaint with requirements of elementary school, as there are many changes between kindergarten and pre-primary school. Kindergarten teachers recognize that teaching mode of senior kindergarten should not be too laissez-faire. Teachers pay more attention to cultivate young children's listening ability, task awareness, and learning habits, peer cooperation, and start training consciously in senior kindergarten classroom, so as to help young children to get closer to requirements of primary school.

Interoperable teachers in charge of the first grade of primary school, try to change teaching methods and renovate teaching content. Compared with original classroom in primary school, although teachers design some games for teaching, but think more highly of form than the content of games. Interoperable teachers let children explore in games, learn from games and gain perception.

\subsection{Design Evaluation Index of Young Children for K-P Transition Period}

According to theoretical guidance of children's physical and mental development, cognitive characteristics, based on rich experiences of front-line teachers, this study identified the "adaptability" of the "evaluation indicators for adaptive development of young children ", as designed 25 evaluation points to integrate into the classroom evaluation, which is more convenient for teachers to operate evaluation tools, finally help teachers achieve the adaptability of K-P transition period. 
Evaluation Index of Young Children for K-P Transition of Yang Pu district is based on a few common understandings ( $\mathrm{Zhu}, 2013$ ):

First, this evaluation index is a benchmark: reflects value orientation of K-P transition education, which points to current development status and awareness of each child, as well as points to the future, regards importance of long-term development of children's concerns.

Secondly, this evaluation index is a tool: to help teachers and parents to discover and observe children's development status and characteristics. These evaluation indicators enable teachers to gain objective and comprehensive understanding of the overall situation of young children in K-P transition period. This evaluation index helps teachers to analyze the appropriateness of educational goals, educational content, and educational methods, adjust teaching strategy immediately. After the implementation of the evaluation, the purpose and direction of teacher work during K-P transition period are clearer.

Accordingly, this study sort out the establishment of evaluation criteria must adhere to the common education principle. The evaluation principle is the basis for guiding the implementation of evaluation, which determines what teachers and parents should do or should not do.

First, the principle of diversity. Parents need to participate in the evaluation. Children are not only limited to kindergartens, schools, but also families, so researchers encourage parents to participate in the evaluation (Zhu, 2013).

Second, the principle of objectivity. In view of the characteristics of children's age, evaluation must be carried out in the real situation, to avoid artificial creation scenarios, evaluation and curriculum implementation closely. The evaluation should be integrated with the real and natural scenarios, with the curriculum integration, and discipline learning integration ( $\mathrm{Zhu}, 2013$ ).

Thirdly, the principle of difference. Children are different, in the evaluation to face and respect these differences, focusing on children in different starting points on the growth and development, rather than see whether they have reached one common standard. Based on different character and different levels of development of children, transition and development are not done overnight, the evaluation should pay special attention to child's individual difference, regard that each child has specific personality, gender, congenital qualification, educational background, which form different state of child's development. Evaluation should be based on the assessment of the characteristics of children found that diagnostic analysis, as the starting point for the implementation of education.

Finally, the principle of inspiration. The evaluation should focus on the inner emotion, the will and the attitude of the children, and should promote the comprehensive development of the children's psychology and ability with the diversified evaluation. The evaluation result is not used for comparison or training by teachers or parents. Appropriate evaluation will protect children's positive selfrecognition, help children to build self-confidence. Promote "incentive evaluation" to wake children's consciousness that "I want to grow" (Zhu, 2013). 


\begin{tabular}{|c|c|c|}
\hline $\begin{array}{l}\text { Indicator } \\
\text { I }\end{array}$ & $\begin{array}{l}\text { Indicators } \\
\text { II }\end{array}$ & Description of Observation Points \\
\hline \multirow{8}{*}{$\begin{array}{l}\text { Learning to } \\
\text { Adapt }\end{array}$} & \multirow{4}{*}{$\begin{array}{l}\text { Emotional } \\
\text { Attitude }\end{array}$} & 1. Learning interest: willing to come to school, interested in courses and activities; \\
\hline & & 2. Curious to explore: love to ask questions, curious about the unknown content, desire to explore; \\
\hline & & $\begin{array}{l}\text { 3. Self-confidence and happiness: belief in completing the task of learning, willing to overcome the difficulties } \\
\text { during learning, feel happy when success; }\end{array}$ \\
\hline & & 4. Focus and adherence: face of difficulties and interference, think of ways to complete the task; \\
\hline & \multirow{4}{*}{$\begin{array}{l}\text { Customary and } \\
\text { method }\end{array}$} & 5. Mission Awareness: complete the task of learning in the prescribed time \\
\hline & & 6. Listen carefully: listen to the words of your peers and teachers, understand the meaning, and respond; \\
\hline & & 7. Communication: express their views and ideas in learning activities; \\
\hline & & 8. Good posture: gradually develop a good reading and writing posture; \\
\hline \multirow{5}{*}{$\begin{array}{l}\text { Life } \\
\text { Adaptation }\end{array}$} & \multirow{3}{*}{$\begin{array}{l}\text { Emotional } \\
\text { Attitude }\end{array}$} & $\begin{array}{l}\text { 9. Communication and cooperation: willing to interact with partners, cooperate and consultant when needed, be } \\
\text { friendly; }\end{array}$ \\
\hline & & $\begin{array}{l}\text { 10. Self-awareness: confidence of the role of their own identity,; willing to do their own thing, try not to rely on } \\
\text { others, have the ability to initially evaluate of their words and deeds; }\end{array}$ \\
\hline & & 11. rule awareness: to understand the basic rules of life schools, comply with the basic rules; \\
\hline & \multirow[b]{2}{*}{$\begin{array}{l}\text { Customary and } \\
\text { Method }\end{array}$} & 12. Reasonable rest: reasonable arrangements for daily life, keep regular life; \\
\hline & & $\begin{array}{l}\text { 13. Learn to take care of themselves: the basic requirements of life and learning, learn to sort out their supplies in } \\
\text { order. }\end{array}$ \\
\hline
\end{tabular}

Figure 2. Evaluation index of Children's adaptive development during K-P transition.

Table 1. Observations for K-P transition period.

\begin{tabular}{cccccc}
\hline $\begin{array}{c}\text { Indicators Of } \\
\text { Dimensions }\end{array}$ & Physical and Mental Health & Emotional Attitude & Habit Training & Interpersonal Communication & Learn to Adapt \\
\hline $\mathbf{1}$ & Physical Compliance & Like School & Reasonable Rest & Willing to Express & discovery \\
$\mathbf{2}$ & Action Coordination & Curious to ask & Life Management & Willing to Consult & Learn to Listen \\
$\mathbf{3}$ & Happy mood & Willing to Try & Reading Habit & Willing to share & Focus on Action \\
$\mathbf{4}$ & Sleep enough & Willing to learn & Exercise habits & Consult & Task Awareness \\
$\mathbf{5}$ & Adapt to the & Self - Identity & Writing & Respect Companions & Safety Rules \\
\hline
\end{tabular}

\subsection{Establishment of “Evaluation Index of Children’s Adaptive Development during K-P Transition"}

The evaluation content is the core part of the appraisal activity plan and the reflection of the value cognition. It indicates what the K-P transition education should pay attention to, what to attach importance to, what can be diluted, and how to guide K-P transition. The most important keywords during K-P transition is "adaptation", which includes young children's will and action of learning to adapt, as well as personal life adaption during K-P transition period (Figure 2) (Zhu, 2013).

In the specific development of evaluation indicators, researchers design five evaluation dimensions, include 25 specific evaluation observations. In formulating the content of evaluation, this study embarks from the practical problems, status analysis, educational goals and experience, children's physical and mental development, as well as children's cognitive development, finally set up the evaluation content (Table 1) (Zhu, 2013). 


\section{References}

Bronfen Brenner, U. (1979). The Ecology of Human Development. Cambridge, MA: Harvard University Press.

Cai, X. L. (2011). Early Childhood Education and Primary Education. Elementary School, 2, 108.

Cui, S. J., Liu, Y., \& Li, M. Y. (2011). A Comparative Study of Trends of Transition from Kindergarten to Primary School Domestic and Abroad. Pre-School Education Research, 4, 53-60.

Fabian, H., \& Dunlop, A. W. A. (2002). Introduction. In H. Fabian, \& A. W. A. Dunlop (Eds.), Transition in the Early Years-Debating Continuity and Progression for Young Children in Early Education (pp. 1-7). London: Routledge Falmer.

Fan, Y. L., Fan, D. M., \& Chen, C. (2010). Study on the Practice of Constructing the Young Linkage Mechanism between Kindgarten and Primary School. Shanghai Educational Research, 5, 69-70.

Gu, G. L. (2014). Analysis of Fracture between Kindgarten and Primary School. Urban Tutor, 8, 100-101.

Kagan, S. L. (1991). Moving from Here to There: Rethinking Continuity and Transitions in Early Care and Education. In B. Spodek, \& O. Saracho (Eds.), (pp. 44-55). New York: Teachers College Press.

Li, L. (2011). A Summary of Researches on Transition from Kindergarten to Primary School. Teacher Education Forum, 7, 58-60.

Lin, H. H. (2011). District and School Linkage, Primary School and Kindergarten Twinning. Educational Circles, 21, 170-171.

Ministry of Education of the People's Republic of China. (2001). Kindergarten Education Guidelines (Trial) (Information Index: 360A26-05-2001-0011-1). http://www.moe.edu.cn/publicfiles/business/htmlfiles/moe/s7054/201403/xxgk_166067 .html

Neuman, M. J. (2002). The Wider Context: An International Overview of Transition Issues. In H. Fabian, \& A. W. A. Dunlop (Eds.), Transition in the Early Years-Debating Continuity and Progression for Young Children in Early Education. London: Routledge Falmer.

Shanghai Municipal Education Commission. (2013). Opinions of Shanghai Municipal Education Commission on the Implementation of Teaching and Evaluation Based on Curriculum Standards in Primary School. (File Number: Basic Education Division (2013), 59).

Shao, Z. Y. (2013). The Origin and Significance of the Research on Transition Education from Kindergarten to Primary School in Yangpu District. Modern Teaching, 11, 14.

Wang, S. P., \& Yang, X. P. (2011). A Review of the Research on Transition Education from Kindergarten to Elementary School in China in Recent Twenty Years. Journal of Chongqing Academy of Arts and Sciences, 30, 148-153.

Wu, G. P., \& Zhu, Q. Y. (2014). Return to Children's Self-Proposition and Review of Transition from Kindergarten to Primary School. Education Research and Comments, 3, 4-8.

Zhang, L., \& Fu, C. (2012). Analysis of the Literature on Transition from Kindergarten to Elementary School. Preschool Education, 4, 40-43.

Zhu, Q. Y. (2013). Start and Think: Research on Regional Transition Education from Kindergarten to Primary School in Yangpu District. Modern Teaching, 11, 14-17. 
Submit or recommend next manuscript to SCIRP and we will provide best service for you:

Accepting pre-submission inquiries through Email, Facebook, LinkedIn, Twitter, etc. A wide selection of journals (inclusive of 9 subjects, more than 200 journals)

Providing 24-hour high-quality service

User-friendly online submission system

Fair and swift peer-review system

Efficient typesetting and proofreading procedure

Display of the result of downloads and visits, as well as the number of cited articles Maximum dissemination of your research work

Submit your manuscript at: http://papersubmission.scirp.org/

Or contact ce@scirp.org 